\title{
UPAYA PEMBERDAYAAN PEREMPUAN PADA KELUARGA PENDERITA DIABETES MELLITUS MELALUI PROMOSI KESEHATAN
}

\author{
Women's Empowerment On The Family Of Diabetes Mellitus Through Health \\ Promotion
}

\author{
Laili Nur Azizah $^{1}$, Indriana Noor Istiqomah ${ }^{1}$, Dwi Ochta Pebriyanti ${ }^{1}$ \\ ${ }^{1}$ Prodi D3 Keperawatan Fak. Keperawatan Unej Kampus Lumajang \\ J1 Brigjen Katamso Lumajang 67312 \\ Email: lailinurazizah3@gmail.com
}

\begin{abstract}
ABSTRAK
Diabetes Mellitus (DM) adalah salah satu penyakit kronik yang terjadi pada jutaan orang di dunia, dengan karakteristik terjadinya peningkatan kadar glukosa darah (hiperglikemia). Diabetes mellitus dapat menjadi serius dan menyebabkan kondisi kronik yang membahayakan apabila tidak diobati. Akibat dari hiperglikemia dapat terjadi komplikasi metabolik akut seperti Ketoasidosis Diabetik (KAD) dan komplikasi kronik pada kardiovaskuler, ginjal, penyakit mata dan komplikasi neuropatik. Hal ini akan memberikan efek terhadap kualitas hidup penderita. Penurunan kualitas hidup mempunyai hubungan yang signifikan terhadap angka kesakitan dan kematian, serta mempengaruhi usia harapan hidup penderita DM. Untuk mencegah terjadinya komplikasi dari DM, maka diperlukan kontrol terapeutik melalui perubahan gaya hidup penderita DM yang tepat, tegas dan permanen. Dukungan keluarga merupakan faktor utama untuk mempertahankan metabolik kontrol yang akan mempengaruhi kualitas hidup penderita. Untuk itu perlu ditingkatkan pemberdayaan perempuan dalam keluarga guna ikut berpartisipasi dalam menurunkan angka kejadian DM dan mencegah terjadinya komplikasi lebih lanjut.

Tujuan kegiatan ini adalah meningkatkan pemberdayaan perempuan dalam keluarga penderita Diabetes Mellitus melalui promosi kesehatan pada anggota Dharma Wanita Persatuan Kantor Kementerian Agama Kabupaten Lumajang. Sedangkan manfaat kegiatan ini adalah meningkatkan pemberdayaan perempuan (sebagai istri dan anak) untuk ikut berperan dalam pengelolaan anggota keluarga yang menderita DM agar tidak terjadi komplikasi lebih lanjut.

Metode kegiatan dilakukan dengan tahapan sebagai berikut: 1) Penyampaian materi kepada anggota Dharma Wanita Persatuan tentang konsep penyakit Diabetes Mellitus serta Pemberdayaan Perempuan di dalam keluarga,; 2) Pemeriksaan Kadar Gula Darah; 3) Evaluasi hasil pelaksanaan.

Hasil dari kegiatan ini adalah peran perempuan sebelum pemberian pendidikan kesehatan adalah cukup tetapi setelah pemberian pendidikan kesehatan ikut berperan baik dalam pengelolaan anggota keluarga yang menderita Diabetes Mellitus. Tindak lanjut yang perlu dilakukan adalah Perlu adanya kegiatan yang sejenis secara berkala pada para suami anggota Dharma Wanita Persatuan Kankemenag instansi kedinasan lainnya serta profesi lain misalnya guru, dan sejenisnya.
\end{abstract}

Kata kunci: pemberdayaan, perempuan, diabetes mellitus

\begin{abstract}
Diabetes Mellitus (DM) is a chronic disease that occurs in millions of people in the world, with the characteristics of increased blood glucose levels (hyperglycemia). Diabetes mellitus can be serious and chronic conditions that cause harm if left untreated. A result of hyperglycemia can be acute Metabolic complications such as Diabetic Ketoacidosis (DKA) and complications of chronic cardiovascular disease, kidney, eye and neuropathic complications. This would give effect to the quality of life of sufferers. The decline in the quality of life has a significant relationship of the number of pain and death, as well as affect the life expectancy aged sufferer of DM. To prevent the occurrence of complications of DM, then needed therapeutic control through a style change living the right DM sufferers, firm and permanent. Family support is a major factor to sustain metabolic controls that will affect the quality of life of sufferers. It needs to be improved for the empowerment of women in the family in order to participate in lowering the numbers of Genesis DM and prevent the occurrence of further complications.

The purpose of this activity is to increase the empowerment of women in the family of sufferers of Diabetes Mellitus through health promotion in a member of Dharma Wanita Persatuan the Ministry of Religion Office of Lumajang. While the benefits of this activity is to increase the empowerment of women
\end{abstract}


(wife and children) to play a role in the management of the family members who suffer from DM in order not to further complications.

Method of activities is done with the following stages: 1) give education about Diabetes Mellitus as well as the empowerment of women in the family; 2) measure of the blood sugar levels; 3) evaluation of the results of the activity.

The results of these activities is the role of women before granting health education is enough but after granting health education contributed well in the management of the family members who suffer from Diabetes Mellitus. Follow up needs to be done is the need for similar activities periodically on the husband a member of Dharma Wanita Persatuan the Ministry of Religion Office limited more and other professions such as teachers, and its kind.

Keywords: Empowerment, women, Diabetes Mellitus

\section{PENDAHULUAN}

Penyakit kronik adalah suatu kondisi dimana terjadi keterbatasan pada kemampuan fisik, psikologis atau kognitif dalam melakukan fungsi harian atau kondisi yang memerlukan pengobatan khusus dan terjadi dalam beberapa bulan.

Diabetes Mellitus (DM) adalah salah satu penyakit kronik yang terjadi pada jutaan orang di dunia. Diabetes Mellitus merupakan sekelompok penyakit metabolik dengan karakteristik terjadinya peningkatan kadar glukosa darah (hiperglikemia), yang terjadi akibat kelainan sekresi insulin, aktifitas insulin dan keduanya. Jika telah berkembang penuh secara klinis, maka diabetes mellitus ditandai oleh hiperglikemia, aterosklerotik, mikroangiopati dan neuropati.

Diabetes mellitus dapat menjadi serius dan menyebabkan kondisi kronik yang membahayakan apabila tidak diobati. Akibat dari hiperglikemia dapat terjadi komplikasi metabolik akut seperti Ketoasidosis Diabetik (KAD) dan keadaan hiperglikemia dalam jangka waktu yang lama berkontribusi terhadap komplikasi kronik pada kardiovaskuler, ginjal, penyakit mata dan komplikasi neuropatik. Diabetes mellitus juga berhubungan dengan peningkatan kejadian penyakit makrovaskuler seperti stroke. Hal ini akan memberikan efek terhadap kualitas hidup penderita. Penurunan kualitas hidup mempunyai hubungan yang signifikan terhadap angka kesakitan dan kematian, serta mempengaruhi usia harapan hidup penderita DM.

Untuk mencegah terjadinya komplikasi dari diabetes mellitus, maka diperlukan pengontrolan yang terapeutik melalui perubahan gaya hidup penderita DM yang tepat, tegas dan permanen. Pengontrolan diabetes mellitus diantaranya adalah pembatasan diet, peningkatan aktifitas fisik, regimen pengobatan yang tepat, kontrol secara teratur.

Penelitian yang dilakukan Robinson (2006) terhadap 19 penderita diabetes mellitus menyimpulkan bahwa dukungan keluarga merupakan faktor yang paling utama untuk mempertahankan metabolik kontrol yang akan mempengaruhi kualitas hidup penderita. Sementara Reinhardt (2001) melaporkan bahwa dukungan keluarga yang negatif merupakan prediktor untuk terjadinya depresi. Lebih lanjut depresi akan memberikan implikasi yang negatif terjadap manajemen Diabetes Mellitus serta kualitas hidup penderita.

Selanjutnya Griffin et al dalam Skarbec (2006) pada sebuah studi longitudinal melakukan investigasi peran keluarga terhadap status kesehatan penderita dengan penyakit kronik. Mereka menemukan hubungan yang kuat antara peran keluarga dengan status kesehatan, dimana dukungan yang negatif akan mengakibatkan rendahnya status kesehatan penderita. Kesimpulan pada penelitian ini menyatakan bahwa dukungan keluarga paling signifikan terhadap kontrol gula darah dan manajemen diabetes mellitus yang berpengaruh terhadap penurunan kualitas hidup.

Dukungan keluarga diartikan sebagai bala bantuan yang diberikan oleh anggota keluarga yang lain sehingga akan memberikan kenyamanan fisik dan psikologis pada orang yang dihadapkan pada situasi stress. Keluarga mempunyai pengaruh kepada sikap dan kebutuhan belajar bagi penderita DM dengan cara menolak atau memberikan dukungan baik secara fisik, psikologis, emosional dan sosial. Penderita DM akan memiliki sikap lebih positif untuk mempelajari diabetes mellitus, apabila keluarga memberikan 
dukungan dan berpartisipasi dalam pendidikan kesehatan mengenai diabetes mellitus. Sebaliknya penderita DM akan bersikap negatif apabila terjadi penolakan terhadap penderita dan tanpa adanya dukungan dari keluarga selama menjalani pengobatan.

Mengingat terapi dan perawatan DM memerlukan waktu yang panjang tentunya bisa menimbulkan kebosanan dan kejenuhan pada penderita DM. Oleh karena itu selain memperhatikan masalah fisik maka perlu juga diperhatikan masalah psikologis penderita dalam penyelesaian masalah Diabetes Mellitus. Keikutsertaan anggota keluarga dalam membantu pengobatan, diet, latihan jasmani dan pengisian waktu luang yang positif bagi kesehatan keluarga merupakan bentuk peran serta aktif bagi keberhasilan penatalaksanaan diabetes mellitus.

Keberhasilan pelaksanaan tata laksana DM ini lebih cepat dengan cara memberdayakan anggota keluarga. Gerakan pemberdayaan (empowerment) adalah proses pemberian informasi secara terus-menerus dan berkesinambungan mengikuti perkembangan sasaran, serta proses membantu sasaran, agar sasaran tersebut berubah dari tidak tahu menjadi tahu atau sadar (aspek knowledge), dari tahu menjadi mau (aspek attitude), dan dari mau menjadi mampu melaksanakan perilaku yang diperkenalkan (aspek practice). Pembinaan terhadap anggota keluarga lainnya untuk bekerjasama menyelesaikan masalah diabetes mellitus dalam keluarganya, hanya dapat dilakukan bila sudah terjalin hubungan yang erat antara tenaga kesehatan dengan pihak penderita dan keluarganya. Dalam hal ini perawat sebagai salah satu dari tenaga kesehatan mempunyai peranan dalam pengelolaan penderita $\mathrm{DM}$, melalui pemberian informasi dan pendidikan kesehatan dalam pengontrolan DM dan pencegahan komplikasi.

\section{METODE}

Kegiatan pengabdian ini dilaksanakan di Aula Kantor Kementerian Agama Kabupaten Lumajang bekerja sama dengan pengurus Dharma Wanita Persatuan Kantor Kementerian Agama Kabupaten Lumajang, di Kelurahan Tompokersan-Lumajang, , serta mahasiswa Akper Pemkab Lumajang. Metode yang digunakan dalam kegiatan ini adalah memberikan penyuluhan tentang materi Diabetes Mellitus, Peran Perempuan sebagai istri dan anak penderita Diabetes Mellitus, menggunakan media Power Point Presentation dan leaflet, yang dilakukan dalam waktu 1 hari. Evaluasi hasil kegiatan dilakukan satu bulan setelah pelaksanaan penyuluhan.

\section{HASIL}

Kegiatan pengabdian ini dilaksanakan di Aula Kantor Kementerian Agama Kabupaten Lumajang Jl. Pisang Agung, Kelurahan Tompokersan, Kecamatan Lumajang, Kabupaten Lumajang, bekerja sama dengan pengurus Dharma Wanita Persatuan Kankemenag Kab Lumajang, diikuti oleh seluruh anggota Dharma Wanita Persatuan Kankemenag Kabupaten Lumajang yang berjumlah 50 orang. Kegiatan diawali dengan tahap pemberian materi \& tanya jawab, selanjutnya dilakukan pemeriksaan kadar gula darah dan diakhiri dengan evaluasi. 1. Tahap pemberian materi

Selama berlangsungnya kegiatan, peserta antusias mendengarkan materi yang disajikan karena presentasi dilengkapi dengan foto-foto prognosa dan komplikasi penyakit Diabetes Mellitus. Penyuluhan dilaksanakan menggunakan media Power Point Presentation dan LCD selama 120 menit yang terbagi dalam 45 menit penyampaian materi, dan 35 menit untuk diskusi dan tanya jawab. Pada saat penyuluhan, disampaikan:

a. Pemberian materi tentang konsep penyakit Diabetes Mellitus meliputi definisi, tanda dan gejala, penyebab, faktor resiko, pemeriksaan penunjang, komplikasi dan manajemen perawatan, agar meningkatkan aspek knowledge anggota Dharma Wanita Persatuan.

b. Peran perempuan sebagai istri dan ibu dari penderita Diabetes Mellitus. Dengan cara meningkatkan aspek practice anggota Dharma Wanita Persatuan melalui tindakan deteksi dini dan pencegahan terjadinya komplikasi Diabetes Mellitus lebih lanjut melalui pemeriksaan mudah dan cepat glukosa darah. Serta meningkatkan aspek attitude melalui kepedulian keikutsertaan dalam pengelolaan penderita Diabetes mellitus selama di rumah

Kegiatan pengabdian ini mendapatkan sambutan hangat dari peserta. Hal ini terbukti dengan banyak peserta yang mengajukan pertanyaan terkait pengalaman pribadi selama 
merawat anggota keluarga yang menderita Diabetes Mellitus di rumah.

2. Tahap Pemeriksaan Kadar Gula Darah.

Tahap ini dilakukan dengan untuk mengetahui kadar gula darah tidak hanya bagi anggota Dharma Wanita Persatuan, tetapi diperkenankan juga mengajak anggota keluarga yang dirasa perlu untuk dilakukan pemeriksaan. Setelah dilakukan pemeriksaan kadar gula darah, dilanjutkan dengan konsultasi tentang hasil pemeriksaan dan hal yang dapat dilakukan selanjutnya di rumah. praktik Kegiatan pemeriksaan ini tidak hanya memeriksa kadar gula darah tetapi juga dilakukan pemeriksaan tekanan darah.

\section{Tahap Evaluasi}

Pada tahap evaluasi, $81 \%$ memiliki pengetahuan baik dan ikut berperan baik dalam pengelolaan anggota keluarga yang menderita Diabetes Mellitus. Sisanya 19\% memiliki pengetahuan baik dan cukup berperan dalam pengelolaan anggota keluarga yang menderita Diabetes Mellitus. Hal ini terjadi karena kesibukan anggota Dharma Wanita Persatuan di luar rumah (sebagai karyawati atau sales), sehingga interaksi dengan anggota keluarga sangat minimal.

\section{SIMPULAN}

Pendidikan kesehatan atau penyampaian informasi secara terus menerus tentang penyakit Diabetes Mellitus adalah merupakan salah upaya yang cukup efektif untuk mencegah terjadinya komplikasi DM lebih lanjut serta menurunkan angka kejadian DM. Upaya ini tentu semakin cepat terlaksana dengan baik melalui pemberdayaan keluarga guna memperhatikan masalah fisik, psikologis dan penyelesaian masalah DM. Pendidikan kesehatan ini telah dapat dilaksanakan pada Kantor Kementerian Agama Kabupaten Lumajang. Kegiatan ini dihadiri oleh anggota Dharma Wanita Persatuan sebanyak 50 orang. Peserta nampak sangat antusias Kegiatan ini dapat berlangsung secara tertib dan baik.

\section{SARAN}

Kegiatan ini adalah kegiatan pemberdayaan. Oleh karena itu pemberian informasi harus dilakukan secara terusmenerus dan berkesinambungan mengikuti perkembangan sasaran, serta proses membantu sasaran, agar sasaran tersebut berubah dari tidak tahu menjadi tahu atau sadar (aspek knowledge), dari tahu menjadi mau (aspek attitude), dan dari mau menjadi mampu melaksanakan perilaku yang diperkenalkan (aspek practice). Perlu adanya kegiatan yang sejenis secara berkala pada para suami anggota Dharma Wanita Persatuan Kantor Kementerian Agama (dalam hal ini adalah Aparatur Sipil Negara) atau instansi kedinasan lainnya serta profesi lain misalnya guru, dan sejenisnya.

\section{DAFTAR PUSTAKA}

American Diabetes Association, 2004, Diagnosis and Classification of Diabetes Mellitus, Diabetes Care, 27 (1), 55-60

Potts,N.L, \& Mandleco, B.L, 2007, Pediatric Nursing: Caring for Children and their families, Clifton Park, New York: Thomson Delmar Learning.

Reindart, J.P, 2001, Effects of Positive and Negative support received and provided on adaptation to cronic visual impairment, Applied Developmental Science, 5 (2), 76-85

Rifki, N.N, 2009, Penatalaksanaan Diabetes dengan pendekatan keluarga, dalam Sidartawan, S, Pradana, S, \& Imam, S, Penatalaksanaan Diabetes Terpadu (hal 217-229), Jakarta: Balai Penerbit FKUI

Robinson, V.M, 2010, The Relative Roles of Family and Peer Support in Metabolic Control and Quality of Life for Adolescents with Type I Diabetes, The University of Edinburgh, diakses dari http://www.Mendeley.com/research pada tanggal 7 September 2017

Ronquillo, L.H, Zenteno, J.F.T, Espinosa, J.G, \& Aceves, G, 2003, Factor asspciated with therapy noncomlience in type 2 Diabetes Patient, Soilud Publica de Mexico, 45 (3), 191-197

Skarbek, E.A, 2006, Psychosocial predictors of self behaviours in type 2 diabetess 
mellitus patient: Analysis of social support, self efficacy and depression. Diakses dari http://citeseerx.ist.psu.edu/view doc/downloadpdf pada tanggal 10 september 2017

Smeltzer, S, \& Bare, 2008, Brunner \& Suddarth's Tectbook of Medical Surgical Nursing, Philadelpia: Lippincott

Soegondo, S, 2006, Farmakoterapi pada pengendalian glikemia diabetes mellitus tipe 2, Buku ajar ilmu penyakit dalam, Jakarta: Pusat penerbitan Departemen Ilmu Penyakit Dalam Fakultas Kedokteran Universitas Indonesia.

Sulistiyani, A.T, 2004. Kemitraan dan Model model Pemberdayaan. Yogyakarta: Graha Ilmu

Taylor, S.E, 2006, Health Psychology, (6th ed), Singapore: MC. Grow Hill Book Company 